\title{
SKETCH-UP
}

\section{Snowstorms on Mars}

Nat. Geosci. http://dx.doi.org/10.1038/ngeo3008 (2017)

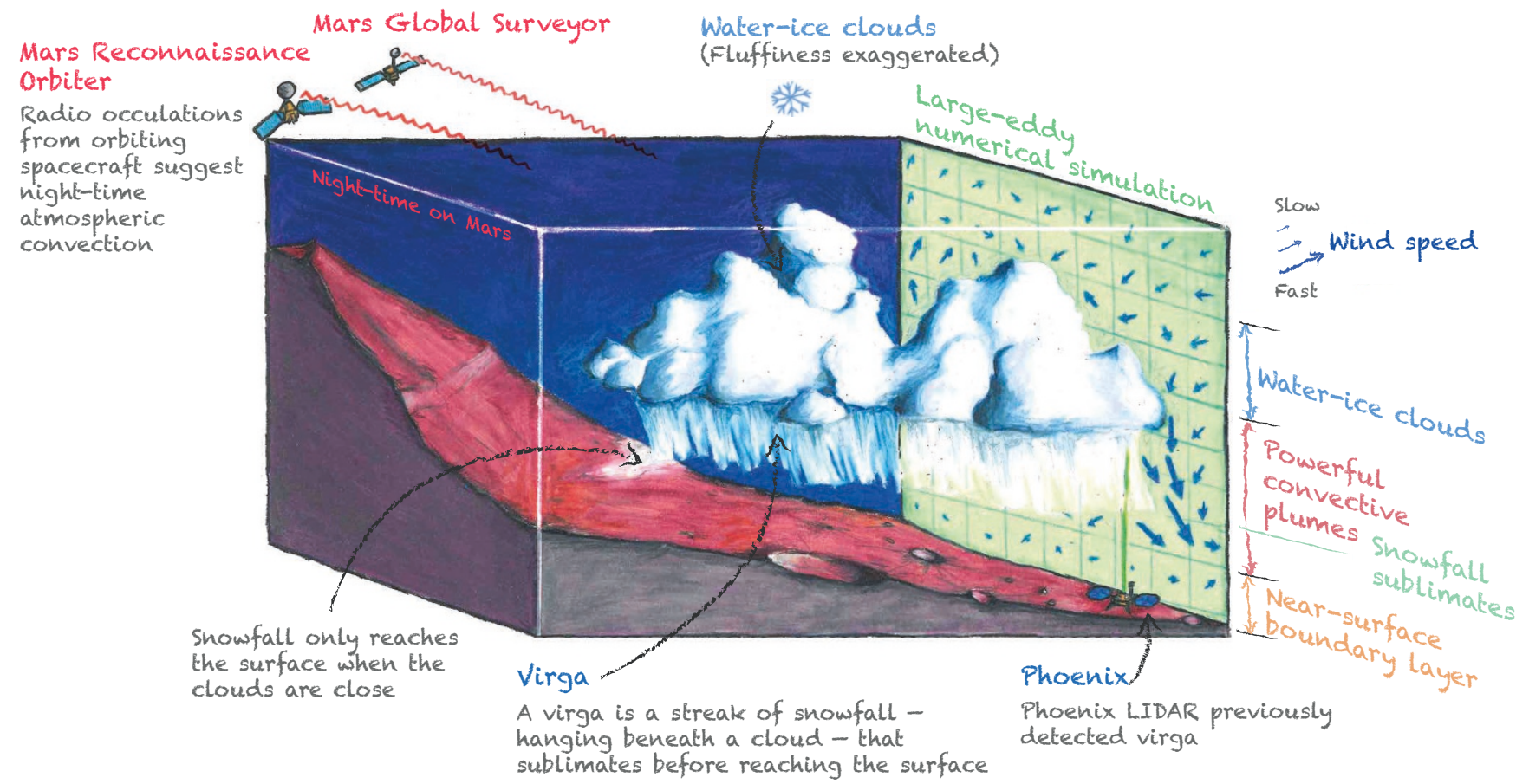

The Martian atmosphere has water-ice clouds, and water ice has been detected on the surface. It has been thought that snow on Mars would fall by slow gentle sedimentation of individual ice particles. Instead, spiga and colleagues use high-resolution weather models to show that convective plumes can form in and below clouds during the cold Martian nights, producing powerful snowstorms.

\section{Enriched carbon source detected}

Estimates of carbon in the deep mantle vary by more than an order of magnitude. Coupled volcanic $\mathrm{CO}_{2}$ emission data and magma supply rates reveal a carbon-rich mantle plume source region beneath Hawai'i with $40 \%$ more carbon than previous estimates.

\section{Peter H. Barry}

ver geologic timescales, the deep carbon cycle transports carbon from the mantle to Earth's surface via volcanism and back into the interior through subduction. This process remains poorly constrained, in contrast to the relatively well-studied near-surface carbon cycle between the atmosphere, oceans and continents. Carbon concentrations in the deepest portions of the mantle - those regions that feed mantle plumes and ocean island basalts - are the most poorly 